\title{
O CONCEITO DE DIREITO E O RECONHECIMENTO ÀS INSTITUIÇÕES JURÍDICAS: ALTERAÇÕES INSTITUCIONAIS E A REGRA DE RECONHECIMENTO
}

\section{THE CONCEPT OF LAW AND LEGAL INSTITUTIONS: INSTITUTIONAL CHANGES AND THE RULE OF RECOGNITION}

\author{
${ }^{1}$ Victor Freitas Lopes Nunes \\ ${ }^{2}$ João Fernando Vieira da Silva
}

\begin{abstract}
RESUMO
O presente estudo busca compreender o caráter dúplice da regra de reconhecimento. Pretendese revelar o âmbito de abrangência da referida regra, o que permitiria descrever os vários elementos que compõe o Direito, dentre eles as instituições que dependem dele para existir; almeja-se conceber, em linhas gerais, em que medida alterações em instituições jurídicas são causas suficientes e necessárias para identificar mutações na regra de reconhecimento. Indaga-se, portanto, qual a relação entre as alterações nas instituições jurídicas e as mudanças regra última de reconhecimento. Acredita-se, como hipótese, que, a despeito da íntima relação entre os elementos delimitadores do problema acima exposto, alterações nas instituições não são indicativos de uma mudança substancial na regra última de reconhecimento. Esta tarefa tem como base teórica a visão conceitual expressa por Hart, a qual exige que se perceba a regra de reconhecimento como uma prática complexa apta a identificar o elemento jurídico. Recorre-se a análise de conteúdo, visto que, a partir dos objetivos anteriormente expostos, propõe-se um estudo de textos teóricos para se construir um sistema analítico de conceitos a ser aplicado sobre as conformações institucionais dispostas pelo ordenamento jurídico. Trata-se, desta forma, de um trabalho teórico com caráter eminentemente descritivo, voltado ao estudo bibliográfico e documental, de base metodológica concebida a partir da análise de conteúdo. Pôde-se observar, deste modo, que mudanças institucionais apesar de não serem são condições suficientes, são necessárias para que se percebam ou constituam alterações na regra de reconhecimento.
\end{abstract}

Palavras-chave: Regra de reconhecimento, Positivismo legal, Instituições jurídicas, Necessidade, Suficiência

\begin{abstract}
This study intends to understend the scope of the rule of recognition, which describes the various elements that make up the legal system, including the institutions that depend on it to exist. We ask, therefore, how is the relationship between changes in legal institutions and the ultimate rule of recognition. Hypothetically, we believe that, despite the close relationship between the bounding elements of the problem above, changes in institutions are not

\footnotetext{
1Mestre em Teoria do Estado e Direito Constitucional pela Pontifícia Universidade Católica do Rio de Janeiro. Professor titular nas Faculdades Doctum, campus Leopoldina e Juiz de Fora. Faculdades Doctum - Juiz de Fora, MG. Brasil - E-mail: victorflnunes@hotmail.com

2 Mestre em Teoria do Estado e Direito Constitucional Pontifícia Universidade Católica do Rio de Janeiro. Pontifícia Universidade Católica do Rio de Janeiro - PUC-Rio, Rio de Janeiro. Brasil -

E-mail: joaofernandoacesso@yahoo.com.br
} 
indicative of a substantial change in the final rule of recognition. The theoretical bases of this paper are dedicated to the presentation of the conceptual view expressed by Hart, which 
makes it necessary to realize the rule of recognition as a complex practice capable of identifying the legal element. In fact, the methodological approach proposes the reconstruction of a system of analytical concepts based on the rule of recognition and its relationships with legal institutions. Thereby, we could see that institutional changes are not sufficient conditions, despite necessary ones, to change de rule of recognition.

Keywords: Rule of recognition, Legal positivism, Legal institutions, Necessity, Sufficiency 


\section{Introdução}

Um estudo sobre qualquer disciplina ou ramo do conhecimento implica em um conceito, ainda que tácito ou subentendido, sobre o que é o objeto que se estuda. Passa, portanto, por uma definição da coisa analisada. Quando se trata de Direito, o objeto estudado são as regras, mais precisamente as regras jurídicas. Em seu livro "O conceito de direito" Herbert L. A. Hart (2007) apresenta sua teoria fundada sobre a regra de reconhecimento, a qual permite identificar quais normas são jurídicas. A partir desta regra, que se apresenta como fundamento de validade e de existência do Direito, marcada, pois, por seu caráter dúplice, é possível compreender a afirmação de que normas jurídicas existem. Revelar tal âmbito possibilita avançar sobre o plano que opera apenas com aspectos de validade e de eficácia do sistema jurídico.

Emerge assim a necessidade de compreender esse caráter dúplice da regra de reconhecimento, reconstruindo sua lógica de formulação, de modo a entendê-la como o fator integrador do conceito de Direito. Mediante esta compreensão, pretende-se revelar o âmbito de abrangência da referida regra, o que permitiria descrever os vários elementos que compõe o Direito, dentre eles as instituições que dependem dele para existir. Notadamente, almeja-se conceber, em linhas gerais, em que medida alterações em instituições jurídicas são causas suficientes e necessárias para identificar mutações na regra de reconhecimento.

Esta tarefa tem como base teórica a visão conceitual expressa por Hart, a qual exige que se perceba a regra de reconhecimento como uma prática complexa apta a identificar o elemento jurídico, o que necessariamente implica na conexão das regras legais com o plano da existência fática. $\mathrm{O}$ foco deste exame será o conteúdo latente dos conceitos sob análise, uma vez que se busca extrair do arcabouço teórico o significado não aparente dos limites relativos à compreensão da relação entre alterações no reconhecimento às instituições jurídicas e mudanças na regra última de reconhecimento. Para tanto, recorre-se a análise de conteúdo, visto que, a partir dos objetivos anteriormente expostos, propõe-se um estudo de textos teóricos para se construir um sistema analítico de conceitos a ser aplicado sobre as conformações institucionais dispostas pelo ordenamento jurídico. Trata-se, desta forma, de um trabalho teórico com caráter eminentemente descritivo, voltado ao estudo bibliográfico e documental, de base metodológica concebida a partir da análise de conteúdo. 
Indaga-se, portanto, qual a relação entre as alterações nas instituições jurídicas e as mudanças regra última de reconhecimento. Qual a correlação entre a aceitação prática desta regra e a alteração no conceito de direito de uma dada sociedade, cujos reflexos se manifestam em mudanças institucionais? Em sendo a regra de reconhecimento elementocentral do conceito de direito, não se pode negar que alterações no sistema jurídico podem representar um reflexo dela ou, ainda, que alterações forçadas no sistema podem refletir sobre ela. Contudo, nem mesmo essas situações gerais são capazes descrever todas as possíveis eventualidades às quais está sujeito um ordenamento jurídico. Neste sentido, é necessária uma investigação mais apurada da relação entre aquilo que Hart (2007) chamou de regras primárias e secundárias, e da relação destas com a regra última de reconhecimento.

Acredita-se, como hipótese, que, a despeito da íntima relação entre os elementos delimitadores do problema acima exposto, alterações nas instituições não são indicativos de uma mudança substancial na regra última de reconhecimento. $\mathrm{O}$ processo de atualização ou de mudança institucional pode se desenvolver de forma bastante livre, sem que seja necessária uma alteração relevante na referida regra.

Ante o exposto, durante os tópicos seguintes deste trabalho, proceder-se-á a uma análise dos conceitos centrais expostos no livro "O conceito de direito" (HART, 2007). Em seguida, será estudada a relação entre reconhecimento e democracia, de modo que se possa visualizar a diferença entre estes conceitos. Posteriormente, será exposta uma breve visão sobre as instituições jurídicas, segundo a perspectiva interna. Serão analisadas, por fim, questões lógico-jurídicas que propõe uma solução para o problema em discussão, bem como será exposta a conclusão da pesquisa desenvolvida.

\section{Regra de reconhecimento: fundamento do sistema jurídico}

A teoria de Hart acerca do conceito de direito possibilita o desenvolvimento de um sistema analítico de conceitos, a partir do qual será discutida a relação entre a regra última de reconhecimento e as alterações nas instituições jurídicas. Metodologicamente, a construção de um sistema analítico de conceitos, fundado em uma pesquisa qualitativa a partir de traços de significação (BABBIE, 2000), baseia-se em uma concepção de direito como prática complexa, expressa na sociedade como processo de aceitação da regra última de reconhecimento (HART, 2007). 
Importa notar, primeiramente, o quão o discurso de Wittgenstein se faz presente na obra de Hart. Para o primeiro, somos o que somos quem função da decorrência de práticas e instituições que regem nossas vidas. Assim sendo, nosso conhecimento de nós mesmos, da sociedade e das atividades que exercemos advém de regras públicas e sociais (MORRISON, 2006). Disse Wittgenstein:

(...) obedecer a uma regra é uma prática. E pensar que se está obedecendo a uma regra não significa obedecer a uma regra. Portanto, não é possível obedecer a uma regra privadamente; de outro modo, pensar que se está obedecendo a uma regra seria a mesma coisa que obedecê-la (WITTGENSTEIN, 1958. p. 202).

Deste modo, o Direito existe porque, na grande maioria dos casos, existem regras gerais e núcleos de segurança por todos compreendidos (STRUCHINER, 2002). Este trabalho se propõe analisar a regra de reconhecimento como um conceito abstrato e geral, mas que isso não implica no descolamento desta pesquisa da realidade fática, muito pelo contrário. É inerente ao conceito de direito, como expresso por Hart, a íntima relação com as questões de fato, as quais são responsáveis pela existência do direito. Neste sentido, é necessário situar o ponto de partida deste trabalho no ordenamento jurídico-positivo, entendido como um complexo escalonado de normas jurídico-positivas. Revelam-se, desta forma, dois aspectos de extrema importância para o trabalho que se segue. O primeiro deles, já mencionado diversas vezes até aqui, é relativo a uma visão conceitual do direito; o segundo, ao qual se faz referência agora, é o de direito positivo. 
O positivismo jurídico é a corrente teórica que, dentre suas várias especificidades, tem como questão central aquilo que John Gardner (2013, p. 199, tradução livre), chamou de "proposição do positivismo legal” " : “(LP): em qualquer sistema jurídico, se uma determinada norma é válida e, portanto, se faz parte daquele sistema jurídico, ela depende de suas fontes, não de seus méritos" ${ }^{\prime 2}$. Segundo esta assertiva, o positivismo jurídico tem duas características marcantes, (i.) privilegiar a ideia de regras na explicação do conceito de direito e; (ii.) permitir a identificação do direito a partir de um critério de fonte e não de mérito. Segundo Gardner (2013, p. 200, tradução livre):

Ela diz, para ser mais exato, que em qualquer sistema jurídico, uma norma é valida como uma norma daquele sistema, somente em virtude do fato de que em algum tempo e lugar relevantes, algum agente ou agentes relevantes a anunciaram, a praticaram, a evocaram, a reforçaram, a endossaram ou, de alguma forma, engajaram-se nela. Não se pode usar como objeção a sua consideração como lei de fato de era uma norma aberrante, na qual aqueles agentes nunca deveriam ter se engajado. De modo inverso, se nenhum agente relevante tivesse se engajado nela, então ela não seria considerada com uma lei, muito embora possa ser uma excelente norma, na qual todos os agentes relevantes deveriam ter se engajado sem reservas.

1 Esta é uma tradução livre da expressão "proposition of "legal positivism"”, a qual se refere a sigla "LP".

2 No original: "(LP) In any legal system, whether a given norm is legally valid, and hence whether it forms part of the law of that system, depends on its sources, not its merits" (GARDNER, 2013, p. 199); 
A primeira assertiva permite distinguir o positivismo jurídico, e também o jusnaturalismo, de outras correntes como o realismo jurídico, uma vez que este último ignora o fato de que as normas jurídicas são o elemento central de análise da teoria do direito. A tese da separação (ii.), por sua vez, permite estabelecer uma clara diferenciação entre o positivismo jurídico e o jusnaturalismo, uma vez que o critério de fonte é característico do modelo positivista, enquanto as fórmulas tradicionais do direito natural determinam a validade das normas jurídicas com base em um conjunto de preceitos logicamente anteriores e eticamente mais relevantes do que as normas juspositivas. Segundo Struchiner (2009, p. 321), "os jusnaturalistas adotam uma espécie de compromisso ontológico dúbio: por um lado, admitem a existência de regras postas por um critério de fonte, por outro lado, admitem uma realidade mais forte para um conjunto de regras logicamente anteriores e eticamente superiores às normas positivadas".

Esta configuração ontológica permite que, em alguma medida, o critério de fonte fique submetido a um critério de mérito. Por sua vez, a própria proposição que define do positivismo jurídico demonstra a primazia do positivismo conceitual em relação a outras correntes do positivismo jurídico, que "se dá em função da sua autenticidade enquanto nota definitória da posição positivista” (STRUCHINER, 2009, p. 319).

Uma vez afirmada esta primazia, procede-se ao estudo do conceito de direito propriamente dito, o qual será investigado a partir da perspectiva hartiana. Hart trabalha a tensão entre os que aceitam e os que rejeitam as regras. Desenvolve uma teoria jurídica analítica fundada em um discurso liberal, tributária de uma Modernidade organizada, deixando bem explícito que a conduta obrigatória não é firmada só com base em ameaças internas. (MORRISON, 2006,). Perceba-se, pois, que Hart fomenta um edifício jurídico que minimiza elementos de coerção, comando e obediência habitual no Direito, rompendo, de certa forma, com as tradições analíticas de Austin e Kelsen. Para Hart, mais do que o script do Direito enquanto instância legítima do Poder e da violência institucionalizada, é possível pensar em regras centradas em práticas sociais, ou seja, ao invés da simples e pura dominação, cabe a referência à aceitação comum de regras (MORRISON, 2006).

Este ponto de vista teórico tem como preceitos basilares a diferenciação entre regras primárias e secundárias e a relação destas com a regra última de reconhecimento de um ordenamento jurídico. A concepção de direito como "a união de regras primárias e secundárias", as quais estão "no centro de um sistema jurídico" (HART, 2007, p. 109) é desenvolvida entendendo que: 
Por força das regras de um tipo, que bem pode ser considerado o tipo básico ou primário, as seres humanos é exigido que façam ou se abstenham de fazer certas acções, quer queiram quer não. As regras do outro tipo são em certo sentido parasitas ou secundárias em relação às primeiras: porque asseguram que os seres humanos possam criar, ao fazer ou dizer certas coisas, novas regras do tipo primário, extinguir ou modificar as regras antigas, ou determinar diferentes modos a sua incidência ou fiscalizar a sua aplicação (HART, 2007, p. 91).

Fica explícito, desta forma, não só a diferença entre as regras primárias e secundárias, mas também que esse último tipo de regras comporta três classes de normas jurídicas, quais sejam: as regras de reconhecimento, que possibilitam determinar quais normas pertencem ao mundo jurídico; as regras de alteração, que permitem criar, modificar e extinguir regras do tipo primário e; as regras de adjudicação, que explicitam os diferentes modos de incidência, fiscalização e/ou aplicação de regras primárias.

A regra de reconhecimento se volta, portanto, para solucionar o problema da incerteza, permitindo identificar as normas primárias ${ }^{3}$, operacionalizando "uma situação social mais complexa, em que a regra secundária de reconhecimento seja aceite e utilizada para a identificação das regras primárias de obrigação" (HART, 2007, p. 111). Sob esta perspectiva, ela apresenta um caráter dúplice, "a regra última de reconhecimento pode ser vista de duas perspectivas" (HART, 2007, p. 123). Neste sentido:

$\mathrm{O}$ argumento para chamar à regra de reconhecimento "direito" é o de que a regre faculta os critérios para identificação das outras regras do sistema pode bem ser concebida como um elemento definidor de um sistema jurídico e, portanto, digna ela mesma de se chamar "direito"; o argumento em favor de a considerar "facto" é o de que afirmar que tal regra existe é, na verdade, produzir uma afirmação externa de um facto real dizendo respeito à maneira por que as regras de um sistema "eficaz" são identificadas (HART, 2007, p. $123)^{4}$.

Pode-se dizer que a primeira perspectiva desenvolve, sob o ponto de vista interno da teoria do direito, que a regra de reconhecimento é o fundamento último de validade do sistema jurídico, enquanto a segunda se refere ao plano da existência, analisando o direito sob seu aspecto externo, determinando a sua faticidade. Neste segundo plano, o reconhecimento

\footnotetext{
3 As regras de alteração e adjudicação se voltam, respectivamente, para buscar soluções para os problemas da estática e da ineficácia. 4 No original: "And this, roughly, is what (LP) says of laws. It says, to be more exact, that in any legal system, a norm is valid as a norm of that system solely in virtue of the fact that at some relevant time and place some relevant agent or agents announced it, practiced it, invoked it, enforced it, endorsed it, or otherwise engaged with it. It is no objection to its counting as a law that it was an appalling norm that those agents should never have engaged with. Conversely, if it was never engaged with by any relevant agents, then it does not count as a law even though it may be an excellent norm that all the relevant agents should have engaged with unreservedly" (GARDNER, 2013, p. 200).
} 
deve consistir em uma prática efetiva e complexa, normalmente concordante, daqueles que vivem e trabalham tendo como ponto de partida um determinado ordenamento jurídico.

O foco sobre a regra de reconhecimento se deposita sobre a "referência ao escrito ou à inscrição (de regras primárias) enquanto dotados de autoridade, isto é, como o modo adequado à eliminação de dúvidas acerca da existência da regra" (HART, 2007, p. 104). O elemento distintivo da regra de reconhecimento é, pois, aquele que dá a ela seu caráter de autoridade, o qual permite determinar se uma norma faz ou não parte do sistema jurídico.

Resta indagar, por fim, quanto ao que caracteriza o elemento autoridade. Hart (2007, p. 113) adverte que: "na maior parte dos casos a regra de reconhecimento não é enunciada, mas a sua existência manifesta-se no modo como as regras concretas são identificadas, tanto pelos tribunais ou outros funcionários, como pelos particulares ou seus consultores". Nota-se, desta forma, que a manifestação desta característica pode ser percebida em dois momentos: um relativo às identificações de regras feitas pelos tribunais e agentes oficiais e; outro feito pelos destinatários das normas, notadamente, os particulares e seus consultores. Desta maneira, é a prática efetiva desses agentes (oficiais e particulares) no sentido de seguir os desígnios do direito ${ }^{5}$ que permite concluir pela existência ou não da regra de reconhecimento.

\section{Reconhecimento e democracia}

A identificação acerca do que efetivamente simboliza a regra do reconhecimento é passível de muitas oscilações semânticas, algo natural, até porque, dada sua pretensão, é plenamente compreensível a dificuldade de singela compreensão de seus escopos e o superdimensionamento dos potenciais interpretativos de tal regra. Buscando um trabalho menos infenso a tais vacilações, recorre-se, em matéria de regra de reconhecimento, ao postulado tabulado por leituras bastante cirúrgicas acerca da proposta de Hart:

A regra de reconhecimento é uma regra secundária que fornece um critério ou conjunto de critérios que se pretendem conclusivos na tarefa de identificação das demais regras. Diferencia-se das regras primárias na medida em que não descreve condutas proibidas ou permitidas, antes determina quais fatos devem ser vistos como normativamente significantes. Sua função é estabelecer um teste de validade para o sistema: se uma determinada norma passa no teste, é considerada válida e, portanto, pertencente ao grupo; do contrário, é considerada inválida e, nessa medida, estranha ao conjunto. Seu conteúdo varia de acordo com o sistema jurídico.

\footnotetext{
5 Nas palavras do próprio Hart (2007, p. 126): "Enquanto as leis que forem válidas perante os testes de validade do sistema, forem obedecidas pela maioria da população temos ai certamente uma prova de que necessitamos para estabelecer que um dado sistema jurídico existe".
} 
É possível, por exemplo, que em um sistema $X$, a reiteração da conduta e a crença na sua obrigatoriedade sejam suficientes para a determinação da existência de um costume jurídico; e que em um sistema $\mathrm{Y}$ seja necessário, para além dessas duas características, a prévia declaração de um tribunal. De um jeito ou de outro - e essa é a proposta de Hart - o que importa é que cada sistema jurídico possui uma, e somente uma regra de reconhecimento, com um conteúdo próprio, a partir do qual é possível identificar as demais normas componentes do sistema. (JUNQUEIRA, 2011. p. 36).

A compreensão da regra última de reconhecimento, como observado no tópico anterior, faz referência às autoridades, bem como aos particulares. Existe, no entanto, uma controvérsia entre os teóricos e estudiosos do pensamento hartiano no que toca à necessidade do reconhecimento por parte dos particulares para a determinação da existência desta regra. Em um primeiro momento, Hart (2007, p. 128) afirma que existem duas condições mínimas necessárias e suficientes para que se identifique que um sistema jurídico existe.

Por um lado, as regras de comportamento que são válidas segundo os critérios últimos de validade do sistema devem ser geralmente obedecidas e, por outro, as regras de reconhecimento especificando os critérios de validade jurídica e as suas regras de alteração e de julgamento devem ser efetivamente aceites como padrões públicos e comuns de comportamento oficial pelos seus funcionários.

Sendo assim, o reconhecimento dos particulares parece ser necessário ao reconhecimento do sistema jurídico. Conduto, mais adiante no texto, quanto trata daquilo que denomina da "patologia dos sistemas jurídicos" (HART, 2007, p. 129), que ele identifica com o divórcio do setor público e do setor privado, no qual não há mais obediência às regras válidas segundo os critérios usados pelos tribunais, o autor adverte que, em casos especiais "pode haver fases intermediárias, durante as quais os tribunais funcionam, seja no território, seja no exilio e usam ainda os critérios de validade jurídica do sistema antigo, outrora firmemente estabelecido, mas estas ordens são ineficazes no território" (HART, 2007, p. 130).

Desta forma, é possível que um sistema jurídico prescinda do reconhecimento dos particulares. Mesmo que por um curto período de tempo, pois segundo Hart, tais sistemas são transitórios, o que é contrário à própria ideia de ordem jurídica, que se pretende duradoura ao longo do tempo. Exatamente por isso que se diz que tais situações representam uma patologia. Entretanto, deve-se registrar que tal hipótese não deve ser descartada.

Sem pretender mais do que mencionar esta circunstância, deve-se entender que de uma forma ou de outra, prescindindo ou não o reconhecimento às ordens dos oficiais e funcionários públicos de efetividade social, a atividade destas autoridades é inerente ao 
próprio processo de reconhecimento. De tal afirmação não advém, no entanto, a necessidade de que o reconhecimento seja democrático.

Certamente, se um sistema pode prescindir de reconhecimento efetivo por parte dos particulares em relação ao direito determinado como válido pelas autoridades, não há ligação entre reconhecimento e democracia. Na hipótese de se entender que em sendo tal situação uma questão limítrofe e que em sistemas não-patológicos a regra última de reconhecimento deve ser efetivamente aceita tanto pelo particular quanto pelo público, mesmo assim não se deve confund ir reconhecimento e democracia.

Uma primeira distinção deve ser feita entre reconhecimento e obediência:

Não precisa partilhar, embora possa fazê-lo, do ponto de vista interno que aceita as regras como padrões para todos aqueles que a quem se aplicam. Em vez disso, pode pensar a regra apenas como algo que the exige acção sob consequências, ou por inércia, sem pensar que ele ou os outros tenham uma obrigação de o fazer e sem estar disposto a criticar-se a si mesmo ou aos outros pelos desvios. Mas este interesse meramente pessoal em relação às regras, que é tudo que o cidadão comum pode ter ao obedecer-lhes, não pode caracterizar a atitudes dos tribunais para com as regras, com as quais funcionam enquanto tribunais (HART, 2007, p. 127).

Portanto, no que toca aos cidadãos o reconhecimento não se confunde, preliminarmente, com a obediência, no sentido de que não precisam aceitar ou gostar das normas jurídicas para obedecê-las. Podem apenas agir conforme as prescrições do direito, sem precisar obrigatoriamente aceitá-lo, admirá-lo ou fazer qualquer outro tipo de juízo sobre seu valor. No entanto, os oficiais precisam manter uma prática efetiva no sentido de agir conforme o direito, ou seja, garantindo a aceitação da regra última de reconhecimento.

Desta forma, o reconhecimento democrático é, certamente, uma forma de reconhecimento, muito difundida principalmente nas sociedades ocidentais contemporâneas, mas não é a única forma de reconhecimento, uma vez que este pode se dar através de uma ação meramente conforme a norma, sem que seja necessário ao cidadão participar do processo de formulação da regra de direito.

Dito de outro modo, não só sociedades democráticas têm ordens normativas nas quais se identifica o elemento jurídico. Mesmo em sociedades monárquico-absolutistas, nas quais apenas uma pessoa participa do processo de formulação das normas jurídicas, pode-se identificar a existência uma ordem juridicamente válida. Sob uma perspectiva estritamente teórico-jurídica, a identificação do elemento democrático com o reconhecimento à ordem jurídica incorporaria um elemento valorativo ao conceito de direito, o que é uma violação 
inaceitável ao paradigma jurídico-positivo, nos termos da proposição do positivismo legal(LP), conforme exposta por Gardner (2013). Se reconhecimento e democracia se confundissem, o direito válido seria apenas o direito democraticamente construído, o que submeteria o direito a um substrato ético superior, característica que identifica o jusnaturalismo, contrapondo-se, portanto, ao conceito de direito expresso pelo positivismo conceitual.

Não se deve confundir, ainda, esta diferenciação e a não associação da proposta do positivismo conceitual com o sistema democrático, com uma apologia a regimes totalitários. A carga eticamente cética do positivismo conceitual incorpora um grau de relativismo que permite à teoria pretender-se geral. Ao dizer que em regimes totalitários há direito, não se pretende afirmar que se deve reconhecer como bom um regime desta natureza, apenas que o direito é independente do processo político de formulação das instituições que o promulgam ou o outorgam. São os defensores do direito natural que "admitem um hinderwelt ou backworld, um mundo atrás do mundo (no melhor estilo do realismo platônico), que seria mais real do que o mundo perecível e mutável das escolhas humanas contingentes" (STRUCHINER, 2009, p. 321).

\section{As instituições jurídicas: uma perspectiva interna}

Conforme foi assinalado anteriormente, a participação dos oficiais, dos agentes públicos é absolutamente indispensável ao conceito de direito e, portanto, ao reconhecimento da ordem jurídica vigente. Neste sentido, é preciso compreender qual é a relação deles com as instituições jurídicas.

Entretanto, primeiramente, é preciso esclarecer o que se entende por instituições jurídicas. Estas são, no sentido aqui trabalhado, um conjunto de práticas juridicamente determinadas pelas normas jurídicas indicadas como válidas segundo os critérios aceitos pelas autoridades. Não se confundem com as regras jurídicas em si, representando muito mais uma atitude, uma ação no sentido de aceitação de um conjunto específico de regras. Podem-se tomar como exemplos de instituições jurídicas os contratos, o direito à propriedade, bem como o Parlamento, a Presidência da República, dentre tantas outras instituições.

Desta forma, a ideia de instituições jurídicas está intimamente ligada à perspectiva interna, conforme descrita por Hart (2007), a qual segundo Shapiro (2013, p. 2, tradução livre) "é a atitude prática de aceitação das regras, o que não implica que as pessoas que aceitam as 
regras o fazem considerando sua legitimidade moral, apenas que estão dispostas a guiar e avaliar condutas de acordo com as regras"

A perspectiva interna é, portanto, um comprometimento expresso pela atitude prática de conformar o comportamento do individuo de acordo com o que determinam as regras jurídicas, o que permite, inclusive, a avaliação crítica dos comportamentos, indicando, por exemplo, os desvios no sentido apontado pelo direito. Esta perspectiva "é usualmente expressa por proposições que usam uma terminologia normativa como "dever", "certo" e “errado"” (SHAPIRO, 2013, p. 9 tradução livre) $)^{7}$.

Não se pode confundir, ainda, esta definição, com a proposta do novo institucionalismo ou, melhor, dos novos institucionalismos ${ }^{8}$. Um exemplo da postura neoinstitucionalista aplicada ao direito é a defendida por MacCormick (2007), o qual ressalta a importância da influencia da proposta de Hart em seu trabalho. No preâmbulo de seu livro "Argumentação jurídica e teoria do direito" este autor revela que: "embora nem de longe tenha a mesma importância, ele é uma espécie de acompanhante do clássico de H. L. A. Hart The Concept of Law [O conceito de direito]”. (MACCORMICK, 2006, p. XVII).

Existe, portanto, uma proximidade entre a matriz teórica original de Hart e de MacCormick. Deve-se notar, no entanto, que os estudos de MacCormick acabaram se distanciando da visão hartiana sobre o conceito de direito, especialmente seus últimos trabalhos, sobretudo no que se refere à aceitação das normas jurídicas:

Para que uma pessoa tenha uma atitude sinceramente crítica em relação a qualquer determinada ação dela própria ou de outra pessoa, deve haver algum modo alternativo de atuar nas circunstâncias em questão que seria até certo ponto preferível ao que realmente foi adotado. Normas sociais comuns devem girar em torno de preferências compartilhadas por certos modos de ação possível em detrimento de outros. É somente a determinação de buscar a conformidade de ações reais com modelos concebidos de ações que constitui normas de conduta. Para que a ideia de "avaliação crítica" da conduta real em comparação com algum padrão concebido faça sentido, é necessário que consideramos que o "padrão concebido" tenha sido determinado por alguém. Uma intenção, preferencia ou aprovação destas não precisa ser considerada arbitrária (MACCORMICK, 2006, p. 373).

\footnotetext{
6 No original: "The internal point of view is the practical attitude of rule-acceptance - it does not imply that people who accept the rules accept their moral legitimacy, only that they are disposed to guide and evaluate conduct in accordance with the rules" (SHAPIRO, 2013, p. 2).

7 No original: "the internal point of view is usually expressed by statements that use normative terminology such as "ought," "must," "right," and "wrong."” (SHAPIRO, 2013, p. 9).

8 Segundo Hall e Taylor (2003, p. 193) "pelo menos três métodos de análise diferentes, todos reivindicando o título de "neo-institucionalis mo", apareceram de 1980 em diante".
} 
Tal postura revela aquilo que Villa $(2013$, p. 2) indica como sendo um equivoco deste autor. MacCormick confunde a postura descritiva, consequentemente não-avaliativa, característica do teórico do direito com uma atitude avaliativa, logo, prescritiva. Basicamente, pode-se afirmar, que ao buscar uma conformação (neo-)institucionalista para sua visão da teoria do direito MacCormick reconheceu uma realidade superior ao direito, assumindo o compromisso ontológico dúbio que Struchiner (2009) indica como sendo a nota distintiva do jusnaturalismo em relação ao positivismo jurídico.

Entendida esta diferenciação, importa notar que conforme a doutrina clássica, exposta por Tercio Sampaio (2011), são fontes do direito: a lei ${ }^{9}$, os costumes, a jurisprudência, a doutrina, os princípios gerais do direito e a equidade. Estas fontes são mecanismos de veiculação de normas expressos por agentes oficiais - como no caso da lei e da jurisprudência - e por particulares - como no caso dos costumes, da doutrina, dos princípios gerais do direito e da equidade ${ }^{10}$.

Aqui, mais uma distinção importante deve ser notada, o critério de fonte, conforme entendido por Hart (2007), não se confunde com a teoria das fontes do direito acima resumida na sua descrição tradicional, apesar de não se opor a ela. $\mathrm{O}$ que é preciso compreender é que a lei, a jurisprudência, os costumes ou qualquer outra fonte são, na realidade, veículos que expressam normas jurídicas, mas não são elas mesmas normas, ou seja, uma lei, por exemplo, é um texto normativo, ou um conjunto de textos - caso se prefira considerar cada segmento da lei (artigos, incisos, alíneas, etc.) como um texto normativo em si - que não se confunde com a norma jurídica propriamente dita, a qual somente pode ser identificada mediante a interpretação do texto normativo, notadamente aquela feita pelas autoridades.

Neste sentido, o critério de fonte identificado pela proposição do positivismo legal é relativo às normas jurídicas e não especificamente à lei ou qualquer outro texto normativo. Retomando (LP) segundo uma perspectiva hartiana, pode-se dizer que o positivismo jurídico é centrado nas normas jurídicas, as quais são identificadas como tais mediante a atitude prática dos oficiais (e dos particulares) de "aceitar e usar os critérios de validade jurídica do sistema" (HART, 2007, p. 129).

\footnotetext{
${ }^{9} \mathrm{O}$ conceito de lei aqui expresso abarca os documentos normativos que compõe o ordenamento jurídico, desde a constituição, passando pelas leis estrito senso e pelos tratados internacionais, chegando até os atos administrativos de caráter normativo.

${ }^{10}$ Ressalte-se que estas fontes são legítimas expressões dos particulares, mas são, no mais das vezes, trazidas para o âmbito do direito por agentes oficiais através da sua atuação. É exemplo deste fato uma sentença, na qual s e julga conforme a equidade. Esta foi expressa mediante uma atuação oficial do juiz, fundado, no caso brasileiro, no permissivo legal, mas a sentença mediatiza o conceito de equida de que tem como origem imediata a realidade social.
} 
Portanto, tem-se que as instituições jurídicas são, sobretudo, um conjunto de atitudes práticas comprometidas com as determinações de normas jurídicas, identificadas como tais mediante a aceitação, por parte ao menos dos oficiais, dos critérios de validade jurídica do sistema. Eis a relação entre os oficiais e as instituições jurídicas, os primeiros são os agentes competentes para determinar o direito válido, segundo os critérios estabelecidos pelo sistema. Ao fazê-lo conformam o comportamento em um determinado sentido. As práticas dos indivíduos orientadas pelas normas jurídicas indicadas como válidas pelos oficiais dão forma às instituições jurídicas.

\section{0 reconhecimento às instituições jurídicas}

A construção de um ordenamento jurídico pretende, através da positivação de textos legais, a estabilização social e, assim, sua própria manutenção ao logo do tempo ${ }^{11}$. Contudo, é possível - e historicamente comprovável - que, eventualmente, uma ordem jurídica seja abalada, ou que suas instituições sejam alteradas com o passar dos tempos. Importa saber, portanto, se existe uma necessária relação entre as mudanças nas instituições jurídicas e o reconhecimento prestado a um sistema jurídico. Em outras palavras, imaginada uma situação hipotética de instabilidade social que culmine em mudanças nas instituições jurídicas, ela seria causa necessária e suficiente para que se afirmasse que aquilo que caracterizava antes a regra última de reconhecimento sofreu uma mutação substancial?

Importa notar que o que se pretende compreender é a correlação entre a alteração na regra última de reconhecimento e os reflexos que esta mudança apresenta na conformação do paradigma institucional, mas não o contrário. Afirmar que se novas instituições existem, então existe uma nova regra de reconhecimento, é uma inversão da lógica do sistema jurídico, e do próprio conceito de regra de reconhecimento. Não é o reconhecimento das normas jurídicas primárias que determina a existência de um ordenamento jurídico, mas sim a aceitação dos critérios de validade que compõe a regra de reconhecimento que valida as demais normas. Neste sentido, o que se investiga é em que medida uma nova regra de reconhecimento provoca mudanças no panorama institucional.

\footnotetext{
11 Um ordenamento não necessariamente se pretende perpétuo, mas, certamente, almeja uma considerável manutenção ao longo do tempo, já que é inerente ao conceito de direito a relação simbiótica entre as regras jurídicas e o reconhecimento social. O qual só pode ser entendido em um sentido forte, se promover uma estabilidade, ainda que relativa, às normas postas.
} 
Neste contexto, necessidade e suficiência devem ser entendidos, respectivamente, como: aquilo de que não se pode prescindir e; aquilo que basta por si só. As mudanças institucionais que eventualmente ocorram devem ser reflexo de alterações em pelo menos uma das dimensões da regra última de reconhecimento, notadamente, a validade e a existência. Para tanto, é preciso entender estas duas dimensões da regra.

Tomando como exemplo uma formulação hipotética da regra de reconhecimento que dispunha: "é direito tudo aquilo que é aprovado pelo parlamento e sancionado pelo chefe do executivo", a dimensão da validade das normas de um determinado ordenamento pode ser apreendida assumindo o paradigma do escalonamento das regras jurídicas, no qual a norma inferior adquire validade a partir da norma superior até que a se chegue à regra última de reconhecimento, a qual determina o mecanismo último de aferição de validade de todas as normas do sistema jurídico. Esta norma, no entanto, não retira sua validade de nenhuma outra norma, mas sim, do reconhecimento fático prestado pelos oficiais e pelos particulares. Dito de outro modo, a validade de uma norma jurídica é aferida a partir de sua existência, entendida como prática efetiva e complexa de aceitação dos critérios de validade.

Conforme já afirmado as regras secundárias, notadamente as regras de alteração, buscam possibilitar exatamente que, em um determinado sistema jurídico, seja possível implementar mudanças com vistas a atualizá-lo ou reformá-lo. Uma causa possível dessa necessidade - dentre outras tantas imagináveis - é o descontentamento dos particulares em relação aos mecanismos institucionais disponíveis. Contudo, é evidente que ainda que alterações nas instituições responsáveis por operacionalizar uma determinada ordem jurídica ocorram isto não é causa suficiente para afirmar que houve uma alteração substancial na regra de reconhecimento, exceto se a formulação anterior desta regra não permitisse que tais mudanças fossem implementadas sob a proteção do ordenamento jurídico vigente até então.

Quanto a isso, pode-se argumentar, por exemplo, que a transformação de um sistema parlamentar bicameral em um unicameral configura uma mudança institucional importante, entretanto, essa transformação pode não alterar substancialmente uma regra de reconhecimento que disponha, hipoteticamente, que em determinado país "é direito tudo aquilo que é aprovado pelo parlamento e sancionado pelo chefe do executivo". Ressalte-se que, conforme a ressalva anteriormente expressa, se a regra de reconhecimento anterior dispusesse que não era possível transigir sobre o número de câmaras do parlamento, tal alteração, caso ocorresse, deve ser precedida por uma nova formulação da regra. 
Nota-se, pois, que existe uma íntima relação entre a suficiência das modificações e o mecanismo de validação das normas dentro de um ordenamento jurídico, uma vez que as regras secundárias, notadamente, aquelas destinadas à alteração do sistema tem, exatamente, o condão de permitir que adequações sejam realizadas para que ele possa permanecer existindo $^{12}$, enquanto representativo de um reconhecimento geral.

Resta saber, por fim, se uma alteração institucional é um reflexo necessário da transformação da regra última de reconhecimento. Superada a dimensão da validade, identificada a insuficiência das mudanças nas instituições jurídicas como característica de uma nova regra última de reconhecimento, deve-se, agora, prestar atenção à dimensão da existência, buscando compreender se há uma relação de necessariedade entre mudanças institucionais e alterações nesta regra.

A existência de um sistema jurídico é determinada pela atitude prática de aceitação dos critérios de validade jurídica, uma vez alterados os critérios, altera-se também a regra última de reconhecimento. Esta alteração tem reflexo imediato no conjunto normativo, que passa a ter sua validade determinada conforme outro padrão normativo. Se as normas jurídicas tem sua validade aferida conforme outros critérios de validade, existem, portanto, outras normas (primárias e secundárias), diferentes das anteriores e, portanto, as atitudes práticas guiadas por estas regras também são, em alguma medida, diferentes.

Percebe-se, assim, que existe uma necessária proximidade entre a alteração regra última de reconhecimento de um ordenamento jurídico-positivo e as mudanças institucionais. Alterada aquela seus reflexos são diretamente sentidos nas instituições jurídicas, que tem suas práticas reconfiguradas segundo os novos critérios de validade aceitos pelas autoridades. Posto que se a regra de reconhecimento é alterada, também o são, em alguma medida, as próprias instituições jurídicas, cuja existência é manifestada pela prática conforme as normas juridicamente válidas por autoridades competentes para reconhecer as fontes do direito.

\footnotetext{
12 Essa conclusão parcial pode, inclusive, justificar as afirmações que abrem este capítulo, as quais asseveram que a ambição de um ordenamento jurídico é se perpetuar no tempo, uma vez que os mecanismos de alteração tem a função de permitir que adequações sejam feitas, de modo a adaptar o sistema à dinâmica da realidade social à qual está sujeito.
} 
Considerando que mesmo que esta regra seja formulada explicitamente de forma a não fazer referência às instituições - diferentemente, portanto, daquela que foi utilizada como exemplo no começo deste capítulo - e, também, que as fontes tradicionais do direito são, na verdade, veículos de normas jurídicas determinadas como tais pela prática das autoridades, tem-se que as práticas dos indivíduos orientadas pelas normas jurídicas indicadas como válidas pelos oficiais dão forma a outras instituições jurídicas.

Importa notar que são efetivamente outras instituições, uma vez que são práticas relativas a outro conjunto normativo, que é assim definido com vistas a uma nova conformação da regra última de reconhecimento. Havendo uma nova regra de reconhecimento, deve, necessariamente, existir um novo sistema jurídico e, portanto, novas instituições jurídicas. Este fenômeno é próprio do processo de reconhecimento, entendido como prática complexa, efetiva e normalmente concordante tanto por parte dos oficiais quanto dos particulares.

\section{Conclusão}

Empreendeu-se um esforço argumentativo com o intuito de, mediante a compreensão do conceito de direito, construir uma proposta explicativa da relação entre a regra de reconhecimento e o paradigma institucional instalado por uma ordem jurídico-positiva. Através de um trabalho teórico-discursivo fundado na construção de um sistema analítico de conceitos por meio de uma pesquisa qualitativa, que entende o direito como uma prática complexa, acreditava-se que o processo de atualização institucional pudesse ocorrer de forma bastante livre, sem que fosse característica necessária da regra de reconhecimento uma determinada conformação das instituições jurídicas.

Pôde-se observar, no entanto, que mudanças institucionais apesar de não serem são condições suficientes, são necessárias para que se percebam ou constituam alterações na regra de reconhecimento. Neste sentido, quando se observam mudanças no quadro institucional, estas não constituem indícios suficientes para que se identifique uma alteração na regra de reconhecimento, especialmente, porque podem ser resultado de transformações desencadeadas pelas regras secundárias de alteração.

De outro modo, é indispensável uma alteração fática na regra de reconhecimento de um sistema de normas positivas para que haja um novo paradigma institucional e, desta forma, novas instituições jurídicas, dado que, neste tipo de sistema, aquela regra indica as 
fontes do direito válido, cuja prática conforma as instituições. Consequentemente, é uma característica necessária à reconfiguração das instituições uma alteração substancial dos critérios de validade aceitos pelos oficiais, uma vez que se alterações no reconhecimento das fontes do direito, impõe alterações no próprio reconhecimento dado às instituições que veiculam estas fontes e são, por conseguinte, um reflexo do processo de mutação na regra de reconhecimento.

O referido processo implica na adesão fática dos oficiais e dos particulares aos critérios de validade ordenamento. Adesão esta entendida como uma nova conformação, composta no intuito de promover as alterações no paradigma institucional necessárias para que se preste o devido reconhecimento ao direito.

\section{Referências bibliográficas}

BABBIE, Earl. The practice of social research. 9. Ed. Belmont: Wadsworth/Thomson Learning, 2000.

BRASIL. Constituição da República Federativa do Brasil, de 5 de outubro de 1988. Brasília, DF, 5 out. 1988. Disponível em: <http://www.planalto.gov.br/ccivil_03/constituicao/constituicao.htm>. Acesso em 6 jul. 2015.

FERRAZ JR. Tercio S. Introdução ao estudo do direito. 6 ed. São Paulo: Atlas, 2011.

GARDNER, John. Legal positivim: 51/2 myths. Disponível em: <http://ajj.oxfordjournals.org/content/46/1/199. full.pdf+html>. Acesso em 5 jul 2013.

HALL, Peter A; TAYLOR, Rosemary C. R.. As três versões do neo-institucionalismo. Lua Nova [online]. 2003, n.58, pp. 193-223.

HART, Herbert L. A. O conceito de direito. 5 ed. Lisboa: Fundação Calouste Gulbenkian, 2007.

JUNQUEIRA, Carlos Frederico Delage. Identidade do direito, individualização de disposições jurídicas e o caráter peremptório das razões para a ação: um estudo sobre teoria dos sistemas jurídicos de Joseph Raz- Tese de Doutorado. Disponível em http://www.maxwell. vrac.puc-rio.br/19586/19586. Acesso em 11 set 2014.

KELSEN, Hans. A democracia. Tradução Vera Barkow. 2. ed. São Paulo: Martins Fontes, 2000 . 
. Teoria Pura do Direito. Tradução João Baptista Machado. 6. ed. São Paulo:

Martins Fontes, 1998.

LEITER, Brian. The radicalism of legal positivism. Disponível

em:<http://papers.ssrn.com/sol3/papers.cfm?abstract_id=1568333>. Acesso em: 5 jul 2013a.

Why legal positivism? Disponível em:

$<$ http://papers.ssrn.com/sol3/papers.cfm?abstract_id=1521761>. Acesso em 10 ago 2013 b.

MACCORMICK, Neil. Argumentação jurídica e teoria do direito. Tradução de Waldéa Barcellos. São Paulo: Martins Fontes, 2006.

Press, 2007.

Institucions fo law: an essay in legal theory. Nova Iorque: Oxford University

MORRISON, Wayne. Filosofia do Direito: dos gregos ao pós-modernismo. Tradução de Jefferson Luiz Camargo. São Paulo: Martins Fontes, 2006.

SHAPIRO, Scott. What is the internal point of view? Disponível em:

<http://papers.ssrn.com/sol3/papers.cfm?abstract_id=937337>. Acesso em: 15 ago 2013.

SGARBI, A. Introdução à Teoria do Direito. São Paulo: Marcial Pons, 2013.

STRUCHINER, Noel. A primazia do positivismo conceitual. In. DIMOULIS, Dimitri; DUARTE, Écio Oto. Teoria do Direito Neoconstitucional: Superação ou reconstrução do positivis mo jurídico? São Paulo: Método, 2009.

Algumas "proposições fulcrais" acerca do direito: o debate jusnaturalis mo vs. juspositivismo. In. MAIA, Antonio Cavalcanti; MELO, Carolina de Campos; CITTADINO, Gisele; POGREBINSCHI, Thamy. Perspectivas atuais de filosofia do direito. Rio de Janeiro: Lumen Juris, 2005.

Para falar de regras: o positivismo conceitual como cenário para uma investigação filosófica acerca dos casos difíceis do direito. 2005. 191f. (Doutorado em Filosofia) - Departamento de Filosofia, Pontifícia Universidade Católica do Rio de Janeiro, Rio de Janeiro, 2005.

Direito e linguagem: uma análise da textura aberta da linguagem e sua aplicação no direito. Renovar: Rio de Janeiro, 2002. 
VILLA, Vittorio. A Pragmatically Oriented Theory of Legal Interpretation. In. Revijaza evropsko ustavnost (Revus), Vol. 12, pp. 89-120, 2010.

. Neil MacCormick's legal positivism. Disponível em:

$<$ http://www.eui.eu/documents/mwp/conferences/neilmaccormick/papervilla.pdf $>$. Acesso em 12 jan 2013.

WITTGENSTEIN. Ludwig. Philosophical Investigation. Oxford: Blacwell, 1958. 